Supporting Information for

\title{
Enhancement of Tetraphenylporphyrin Electrochemiluminescence by Means of Symmetry Breaking
}

\author{
Ruizhong Zhang ${ }^{\mathrm{a}, \mathrm{b} \ddagger}$, Angel Zhang ${ }^{\mathrm{b} \ddagger}$, Martin J. Stillman ${ }^{\mathrm{b} *}$, Zhifeng Ding ${ }^{\mathrm{b} *}$ \\ ${ }^{a}$ Tianjin Key Laboratory of Molecular Photoelectronic Sciences, Department of Chemistry, Tianjin \\ University, Tianjin 300072, China \\ ${ }^{b}$ Department of Chemistry, The University of Western Ontario, London, ON N6A 5B7, Canada \\ *Corresponding author. Emails: stillman@uwo.ca; zfding@uwo.ca
}

Table S1. Summary of the spectroscopic data for $\mathrm{H}_{2}$ TPP' and parent $\mathrm{H}_{2} \mathrm{TPP}$.

\begin{tabular}{|c|c|c|c|c|c|}
\hline Compound & $\begin{array}{l}\lambda \text { (Absorption) } \\
(\mathrm{nm})\end{array}$ & $\begin{array}{l}\varepsilon\left(\mathrm{M}^{-1} \mathrm{~cm}^{-1}\right) \\
\text { (at } \mathrm{Q} \text { band) }\end{array}$ & $\begin{array}{l}\lambda(\mathrm{PL}) \\
(\mathrm{nm})\end{array}$ & PL QY'a] & $\begin{array}{c}\lambda(\mathrm{ECL}) \\
(\mathrm{nm})\end{array}$ \\
\hline ZnTPP & $422,556,596$ & $5792,999,477$ & 610,655 & 1.48 (at $596 \mathrm{~nm}$ ) & 625,660 \\
\hline $\mathrm{H}_{2} \mathrm{TPP}$ & $419,512,546,589,645$ & $10600,5532,3851,3202$ & 650,715 & 3.12 (at $645 \mathrm{~nm}$ ) & 660,718 \\
\hline
\end{tabular}

[a] The photoluminescence quantum yield $(\mathrm{QY})$ here is relative to $\mathrm{Ru}(\mathrm{bpy})_{3}\left(\mathrm{PF}_{6}\right)_{2}$.

Table S2 Summary of electrochemical potentials and ECL data for ZnTPP and $\mathrm{H}_{2}$ TPP.

\begin{tabular}{|c|c|c|c|c|c|c|c|c|}
\hline \multirow[t]{2}{*}{ Compound } & \multicolumn{2}{|c|}{$\begin{array}{l}\text { Reduction potential } \\
\text { [V vs SCE] }\end{array}$} & \multicolumn{3}{|c|}{$\begin{array}{c}\text { Oxidation potential } \\
\text { [V vs SCE] }\end{array}$} & \multirow[t]{2}{*}{$\begin{array}{l}\Delta \mathrm{E}_{\text {redox }}[\mathrm{ev}]^{[\mathrm{a}]} \\
\left(\mathrm{E}_{\text {Ox } 1}-E_{\text {Red } 1}\right)\end{array}$} & \multicolumn{2}{|c|}{$\begin{array}{c}\lambda_{\max }(\mathrm{ECL}) \\
(\mathrm{nm})\end{array}$} \\
\hline & $\operatorname{Red}_{2}$ & $\operatorname{Red}_{1}$ & $\mathrm{Ox}_{1}$ & $\mathrm{Ox}_{2}$ & $\mathrm{Ox}_{3}$ & & & \\
\hline ZnTPP & -1.68 & -1.32 & 1.07 & 1.38 & - & 2.39 & 625 & 660 \\
\hline $\mathrm{H}_{2} \mathrm{TPP}$ & -1.71 & -1.34 & 1.02 & 1.24 & 1.42 & 2.36 & 660 & 718 \\
\hline
\end{tabular}

[a] Electrochemical HOMO-LUMO energy gap, $\Delta \mathrm{E}_{\text {redox }}=\mathrm{E}_{\mathrm{Ox} 1}-\mathrm{E}_{\mathrm{Red} 1}$ (vs SCE). 


\section{ECL Efficiency Calculation}

ECL efficiency $\left(\Phi_{\mathrm{x}}\right)$ is defined as the ratio of the number of photos produced per electron transfer between the oxidized and reduced analyte species relative to the ECL standard. ${ }^{1-2}$ In this work, the $\Phi_{\mathrm{x}}$ were calculated relative to $\mathrm{Ru}(\mathrm{bpy})_{3}\left(\mathrm{PF}_{6}\right)_{2}$ systems by taking their ECL efficiency as $100 \%$ in 1:1 MeCN: benzene mixed solvent. This was done by taking the sum of the integration of both the ECL intensity and current values (versus time) for each compound against the $\mathrm{Ru}(\mathrm{bpy})_{3}\left(\mathrm{PF}_{6}\right)_{2}$, as described in equation $\mathrm{S} 1$ :

$$
\Phi_{x}=100 \% \frac{\left[\frac{\int_{a}^{b} E C L \mathrm{dt}}{\int_{a}^{b} \text { Current } \mathrm{dt}}\right]_{x}}{\left[\frac{\int_{a}^{b} E C L \mathrm{dt}}{\int_{a}^{b} \text { Current } \mathrm{dt}}\right]_{s t}}
$$

where $\Phi$ is the ECL efficiency (\%) relative to $\mathrm{Ru}(\mathrm{bpy})_{3}\left(\mathrm{PF}_{6}\right)_{2}, E C L$ and Current represent ECL intensity and electrochemical current value, respectively. $S t$ is the $\mathrm{Ru}(\mathrm{bpy})_{3}\left(\mathrm{PF}_{6}\right)_{2}$ standard and $x$ is the experimental sample. ECL experiments for each compound were tested with a minimum of three different potential windows based on their redox potentials, tuning for the strongest ECL activity. 

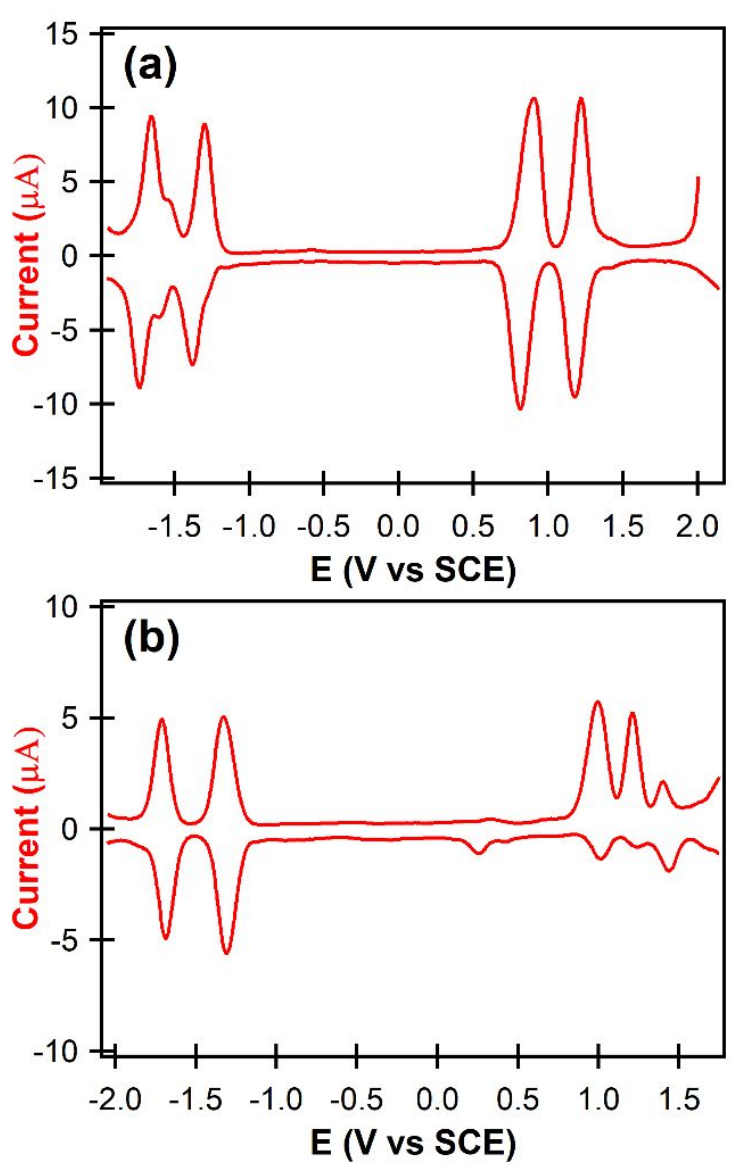

Figure S1. Differential pulse voltammograms of $1.5 \mathrm{mM}$ (a) ZnTPP and (b) $\mathrm{H}_{2}$ TPP in 1:1 MeCN : benzene with $0.1 \mathrm{M}$ TBAP as supporting electrolyte at a scan rate of $100 \mathrm{mV} \mathrm{s}^{-1}$. 

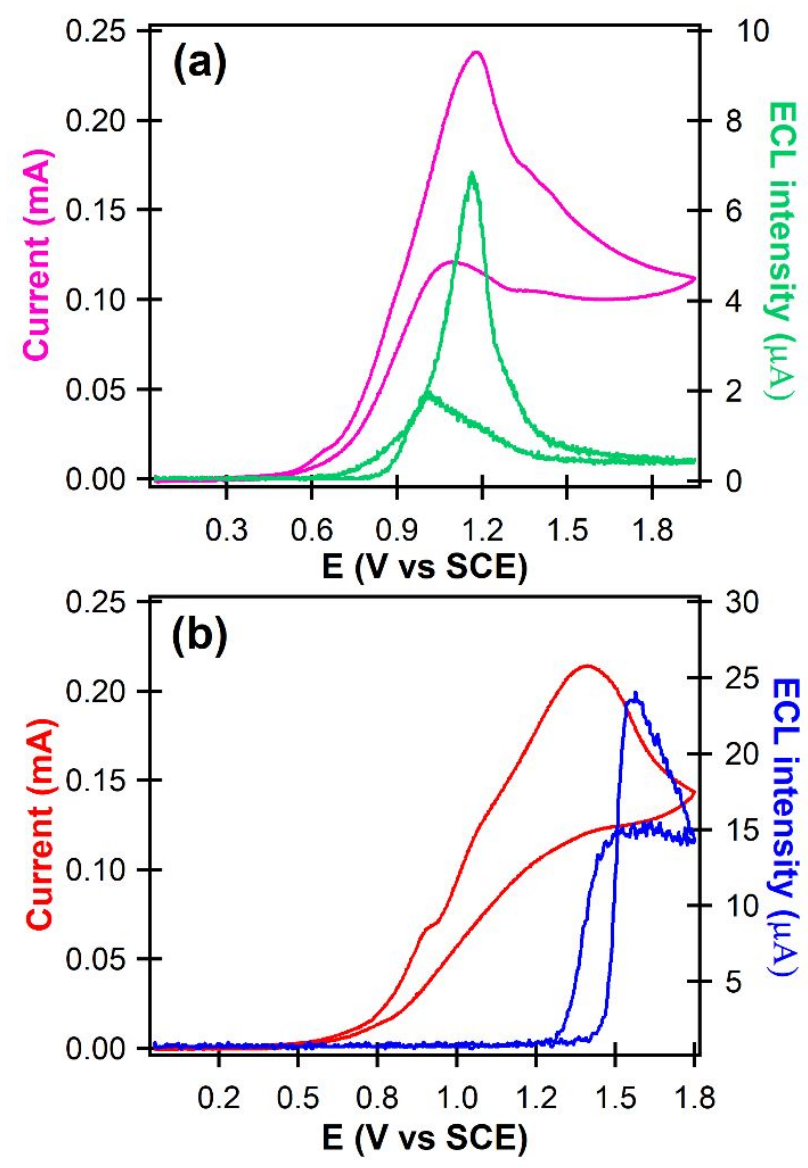

Figure S2. CVs and corresponding ECL-voltage curves collected with a photomultiplier tube (PMT, Hamamatsu R928) for $1.5 \mathrm{mM}$ ZnTPP (a) and $\mathrm{H}_{2} \mathrm{TPP}$ (b) in the presence of $25 \mathrm{mM}$ TPrA in 1:1 MeCN:benzene with $0.1 \mathrm{M}$ TBAP as the supporting electrolyte at a scan rate of $100 \mathrm{mVs}^{-1}$. Cathodic coreactant, persulfate was added to the systems as well. However the ECL intensity of $\mathrm{H}_{2}$ TPP in the presence of $5 \mathrm{mM}$ persulfate (Figure S4) is only $600 \mathrm{nA}$, which is 27 -fold lower than with same concentration of $5 \mathrm{mM} \operatorname{TPrA}(16.2 \mu \mathrm{A})$. Sufficient lifetimes and favorable electron transfer between species are the two criteria governing the observation of light emission. Not quite good balance between above criteria is probably the main reason for its lower ECL of $\mathrm{H}_{2}$ TPP by using persulfate as a coreactant. 

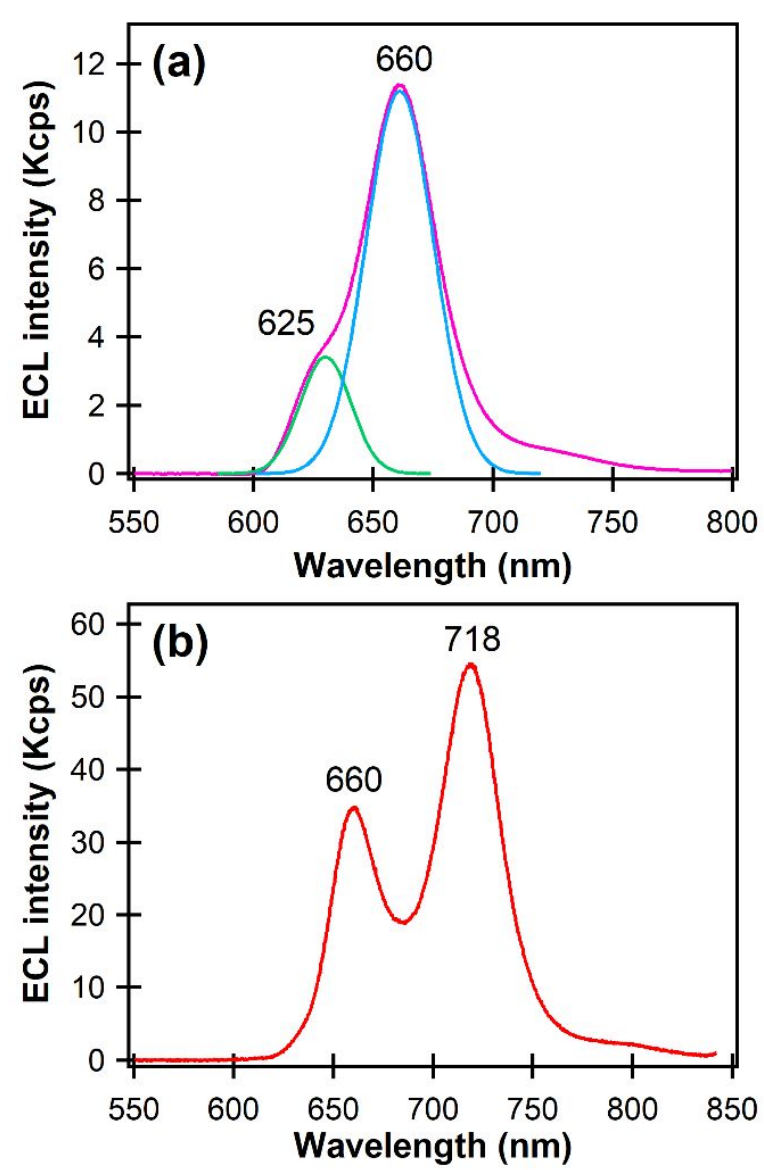

Figure S3. Accumulated ECL spectra of $1.5 \mathrm{mM}$ solution of ZnTPP (a) and $\mathrm{H}_{2} \mathrm{TPP}$ (b) with 25 $\mathrm{mM}$ TPrA collected during two consecutive potential scan cycles at $100 \mathrm{mV} \mathrm{s}^{-1}$. An Andor iDUS CCD camera (cooled at $-65^{\circ} \mathrm{C}$ ) was used to collect the spectra. 


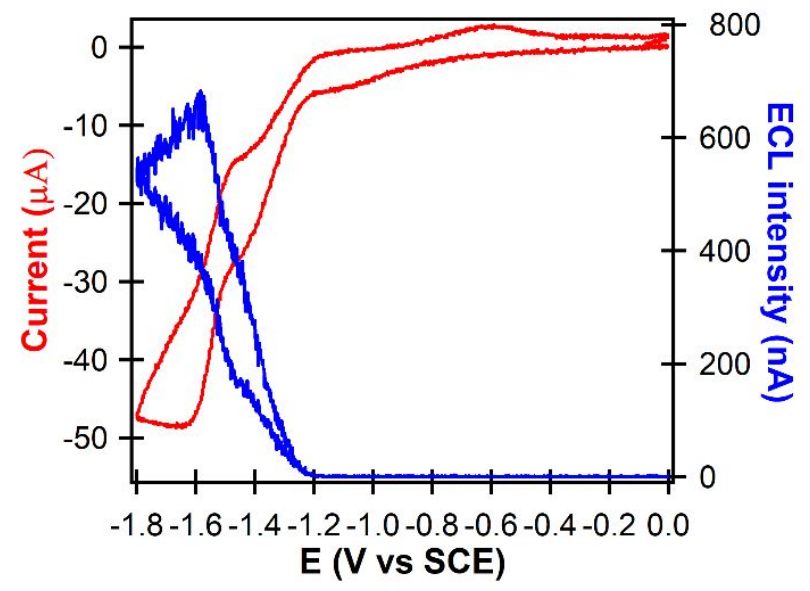

Figure S4. CVs and corresponding ECL-voltage curves collected with a photomultiplier tube (PMT, Hamamatsu R928) for $1.5 \mathrm{mM} \mathrm{H}_{2}$ TPP with $5 \mathrm{mM}$ persulfate in 1:1 MeCN: benzene with $0.1 \mathrm{M}$ TBAP as supporting electrolyte at a scan rate of $100 \mathrm{mV} \mathrm{s}^{-1}$.

\section{References}

1. Hesari, M.; Workentin, M. S.; Ding, Z. F., Thermodynamic and kinetic origins of $\mathrm{Au}_{25}{ }^{0}$ nanocluster electrochemiluminescence. Chem. Eur. J. 2014, 20, 15116-15121.

2. Xiang, G. M.; Wang, X.; Li, M. S. M.; Lac, K.; Wang, S. N.; Ding, Z. F., Probing excimers of Pt(II) compounds with phenyl-1,2,3-triazolyl and pyridyl-1,2,4-triazolyl chelate ligands by means of electrochemiluminescence. ChemElectroChem 2017, 4, 1757-1762. 